RBMC

ISSN 2447-9071

doi https://doi.org/10.36414/rbmc.v7i19.115
Contato para correspondência: Leonardo Luiz Borges

E-mail:

leonardo.cbb@pucgoias.edu.br

Conflito de interesse: Não

Financiamento: Recursos próprios

Recebido: 23/11/2021

Aprovado: 09/12/2021

\section{Predição biológica in silico de marcadores químicos encontrados em Arachis hipogaea}

\section{In silico biological prediction of Chemical markers found in Arachis hipogaea}

Kállita Poliana da Silva', Ana Beatriz Ferro de Melo', Eduardo Chaves Ferreira Coelho', Leonardo Luiz Borges ${ }^{1,2}$

${ }^{1}$ Pontifícia Universidade Católica de Goiás - PUC Goiás

2 Universidade Estadual de Goiás - UEG

\begin{abstract}
Resumo
A Arachis hypogaea cultivada é a segunda leguminosa de maior importância e uma das oleaginosas mais cultivadas no mundo. Dentre os compostos mais relevantes encontrados na planta estão principalmente estilbenos eflavonoides. Esses compostos estão envolvidos em um mecanismo da planta para a defesa contra lesões físicas e contaminação pormicro-organismos. Nesse sentido, o objetivo da presente pesquisa consiste em identificarmoléculas químicas da espécie Arachis hipogaea propensas a inibir alvos biológicos. Dessa forma, será realizado um levantamento bibliográfico dos marcadores químicos já identificados nesta espécie; construir as estruturas 2D e 3D desses compostos, realizar a predição biológica dessas substâncias e promover a interação molecular por meio de dosagem molecular com os alvos encontrados nas análises prévias. A busca por marcadores químicos da espécie Arachis hipogaea foi realizada por meio de revisão bibliográfica baseada em artigos publicados na base de dados do PubMed, utilizando os termos booleanos AND, OR, NOT e filtração de resultados; ScienceDirect e SciELO. Por meio do levantamento bibliográfico, foram identificadas 7 moléculas químicas presentes na espécie Arachis hipoganea. Dentre as moléculas encontradas, estáa araquidina -1que apontou ainda como probabilidade mais relevante a atuação da molécula na subunidade alfa da proteína quinase P13 relacionado ao câncer de colo retal. Por fim, conclui-se que o composto natural Araquidina-1, extraído da espécie Arachis hipogae, com seu amplo espectro de bioatividade apresentou resultados promissores para o tratamento do câncer de colorretal.
\end{abstract}

Palavras-Chave: Arachis hypogaea; Docking; Câncer colorretal; Mutação; Amendoim.

\begin{abstract}
Cultivated Arachis hypogaea is the second most important legume and one of the most cultivated oilseeds in the world. Among the mostrelevant compounds found in the plant are mainly stilbenes and flavonoids. These compounds are represented in a plant mechanism for defense against forms and contamination by microorganisms. In this sense, the objective of this research is to identify molecules of the Arachis hipogaea species that are prone to inhibit biological targets. Thus, a bibliographic survey of chemical markers already identified in this species will be carried out; build the composite 2D and 3D structures, carry out the biological prediction of these substances and promote a molecular interaction through molecular dosage with those found in previous analyses. The search for chemical markers of the Arachis hipogaea species was performed through a literature review based on articles published in the PubMed database, using the Boolean terms AND, OR, NOT and filtering of results; ScienceDirect and SciELO. Through a bibliographic survey, 7 molecules present in the species Arachis hipoganea were identified. Among the molecules found, there is arachidine-1, which also pointed out as the most relevant probability the action of the molecule in the alpha subunit of the protein kinase P13 related to colorectal cancer. Finally, it is concluded that the natural compound Araquidin-1, extracted from the species Arachis hipogae, with its broad spectrum of bioactivity presents promising results for the treatment of colorectal cancer.
\end{abstract}

Keywords: Arachis hypogaea; Docking; Colorectal cancer; Mutation; Peanut. 


\section{Introdução}

As plantas medicinais consistem nas mais antigas "armas" utilizadas pelo ser humano para fins terapêuticos das mais diversas patologias. Trata-se de um hábito que acompanhou a história da humanidade. O conhecimento relacionado a flora perpassou pela evolução do homem através dos tempos. As civilizações primitivas por meio da observação notaram a diferença entre plantas comestíveis com relação às outras dotadas de algum potencial terapêutico. Esse conhecimento foi sendo repassado oralmente atrás das gerações até o surgimento da escrita, que logo passaram a serem registradas manualmente ${ }^{1,2}$.

Dentre os primeiros registros relacionados, há a utilização das plantas datado de 500 a. C., no texto Chinês que descreve minunciosamente não somente os nomes, mas também as doses e indicações de uso de plantas para tratamento de enfermidades. Outros registros de plantas medicinais foram encontrados no manuscrito Egípicio “Ebers Papirus”, de 1.500 a. C'.

A partir do final do século XIX, por meio do isolamento dos constituintes dotados de alguma ação farmacológica, a utilização de compostos advindos das plantas entra numa nova fase. Nesse contexto, destaca-se os trabalhos do pesquisador Claude Bernard (1813-1878), que verificaram as atividades de vários extratos vegetais como forma de identificar melhor seus componentes biológicos².

Nas últimas décadas, houve um aumento considerável quanto ao interesse em substâncias advindas das espécies vegetais, evidenciado pelo crescimento nas publicações relacionadas à farmacologia. Alguns fatores têm contribuído para este aumento de interesse, entre eles está a grande eficácia de algumas substâncias antitumorais obtidas de plantas, como os alcaloides e taxoides. $O$ interesse no estudo de espécies vegetais para fins medicamentosos ocorreu devido à presença de princípios ativos, que são moléculas denominadas fitofármacos, sintetizados pelo metabolismo secundário das plantas como forma de combater predadores ${ }^{3}$.

Dentre as plantas com potencial terapêutico, está a Arachis hypogaea L. que é conhecida popularmente como amendoim. É uma planta pertencente ao gênero Arachis L. (Legunimosae), o qual é dividido em nove seções. A Arachis hypogaea L. pertence a subfamília Papilonoideae, gênero Arachis juntamente com mais 80 espécies silvestres, tanto anuais quanto perenes. $A$ planta é nativa da América do Sul, na região que compreende entre as latitudes $10^{\circ}$ e $30^{\circ}$ sul, com provável centro de origem do noroeste da Argentina ao sul da Bolívia. Trata-se de uma planta alotetraploide, que se reproduz quase exclusivamente por autogamia. É herbácea, ereta ou prostrada, anual, com ciclo entre 90 e 160 dias, podendo atingir a altura da haste principal entre 50 e $60 \mathrm{~cm}^{4,5}$.
A Arachis hypogaea é a segunda leguminosa de maior importância e uma das oleaginosas mais cultivadas no mundo. Suas sementes, as quais são provenientes dos óvulos, se constituem na parte de maior interesse econômico, por se tratar de um alimento nutritivo e com alto teor de óleo comestível. Seu número pode variar entre 1 e 6 e sua proporção varia de acordo com a cultivação e as condições do plantio que, de maneira geral, situa-se entre 65 e $80 \%$. No Brasil, ocorre o maior número de espécies, sendo que 46 são exclusivamente brasileiras ${ }^{4,5}$.

A classe de compostos mais encontrados no gênero Arachis é derivada fenilpropanoides, principalmente estilbenos e flavonoides, aos quais estão envolvidos na defesa contra lesões físicas e contaminação microbiana ${ }^{6}$.

Atualmente, a geração de novos conhecimentos científicos e tecnológicos tem sido difundida e divulgada rapidamente nos setores de pesquisa. Dentre tais conhecimentos está a descoberta de novos candidatos a fármacos, afinal, muitas classes de compostos orgânicos têm demonstrado efeitos biológicos promissores e a literatura científica relata um crescente aumento na descrição de novas moléculas com potencial farmacêutico ${ }^{7}$.

As técnicas computacionais (in silico) para o desenvolvimento de novos fármacos tornou-se nos últimos tempos uma tendência para as indústrias farmacêuticas, pois permite a identificação de moléculas bioativas que, uma vez armazenadas em bancos de dados, poderão ser testados e servir como candidatos a novos fármacos. Partindo dessa vertente, o estudo in silico da Arachis hipogaea pode ser uma contribuição significativa para a identificação dessas substâncias bioativas, visto que vários compostos desta espécie já foram isolados e apresentaram propriedades terapêutica ${ }^{7}$.

Nessa perspectiva de análise, o objetivo da presente pesquisa consiste em identificar moléculas químicas da espécie Arachis hipogaea propensas a inibir alvos biológicos. Dessa forma, será realizado um levantamento bibliográfico dos marcadores químicos já identificados nesta espécie; construir as estruturas 2D e 3D desses compostos, realizar a predição biológica dessas substâncias e promover a interação molecular por meio de dosagem molecular com os alvos encontrados nas análises prévias. As atividades biológicas que obtiveram uma maior pontuação para cada programa foram selecionadas para investigações mais aprofundadas em etapas posteriores.

\section{Métodos}

A busca por marcadores químicos da espécie Arachis hipogaea foi realizada por meio de um artigo de revisão publicado por Lopes, R.M. et al. (2011), que fez um compilado dos compostos conhecidos nesta espécie ${ }^{6}$. 
As moléculas foram analisadas através dos métodos in silico, os quais oferecem informações sobre a atividade biológica e as propriedades físico-químicas dos compostos de interesse. Tornando possível a seleção e triagem de novos fármacos a partir dessas moléculas.

A triagem farmacocinética para os marcadores químicos foi realizada com os programas Molinspiration ${ }^{8}$, SwissADME ${ }^{9}$ e ProtoxPrediction ${ }^{10}$. Na etapa de triagem bioativa foi utilizada como ferramenta o PassPrediction ${ }^{11}$ do qual foi possível obter uma lista com possíveis atividades biológicas para cada uma das substâncias, segundo a filosofia metodológica do programa.

Com base nestas ferramentas foi selecionado uma substância para estudos posteriores, a araquidina-1. Essa seleção ocorreu pela substância apresentar, segundo os servidores Molinspiration e SwissADME ${ }^{9}$, classificação druglikeness, baixa toxicidade e potencial antineoplásico e antimutagênico, conforme apontado pelos servidores ProtoxPredicion ${ }^{10} \mathrm{e}$ PassPrediction ${ }^{11}$ respectivamente. Dado este que corrobora com os estudos de Huang e colaboradores ${ }^{12}$ no qual afirma que a Araquidina-1 demostrou eficácia como anticancerígeno.

Partindo desses resultados, a molécula araquidina -1 foi submetida para avalição no servidor SwissTargetPredicion ${ }^{13}$, o qual apontou como probabilidade mais relevante a atuação na subunidade alfa da proteína quinase $\mathrm{P} 13$ relacionado ao câncer de colo retal.

Os métodos de triagem propostos são complementares, explorando estratégias que avaliam a complementaridade das substâncias avaliadas em relação a alvos biológicos de interesse, como implementado no programa SwissTargetPredicion ${ }^{13}$, ou até comparações de propriedades químicas com moléculas bioativas já conhecidas, como observado nos métodos dos programas PASS ${ }^{11}$, Molinspiration ${ }^{8}$ e ProtoxPrediction ${ }^{10}$.

\section{Resultados e Discussão}

Identificaram-se, por meio do levantamento bibliográfico, 7 (sete) moléculas químicas presentes na espécie Arachis hipoganea. Para a coleta de informações biológicas dessas substâncias, foi realizada uma predição molecular por meio dos bancos de dados Molinspiration ${ }^{8}$, SwissADME ${ }^{9}$ e Protox Prediction $^{10}$, os quais avaliam as propriedades farmacocinéticas dos compostos: propriedades físico-químicas, potencial de absorção gastrointestinal e a toxicidade deles. Estas propriedades influenciam na atividade farmacológica dos compostos e, assim, permitem avaliar o potencial de cada biomolécula.

Os resultados encontrados pelos servidores Molinspiration e SwissADME mostram, conforme Tabela 1 e Tabela 2 , que as moléculas selecionadas apresentaram potencial Druglikeness.
Tabela 1. Propriedade dos compostos encontrados na espécie Arachis hipogaea, segundo o servidor Molinspiration.

\begin{tabular}{ccccc}
\hline Compostos & miLogP & MM & nON & nOHNH \\
\hline Araquidina-1 & 5,03 & 312.37 & 4 & 4 \\
Araquidina-2 & 5.70 & 296.37 & 3 & 3 \\
Araquidina-3 & 5.52 & 296.37 & 3 & 3 \\
arahypin-1 & 6 & 280.37 & 2 & 2 \\
arahypin-2 & 3.09 & 330.38 & 5 & 5 \\
arahypin-3 & 3.56 & 330.38 & 5 & 5 \\
arahypin-4 & 4.04 & 314.38 & 4 & 4 \\
\hline
\end{tabular}

Legenda: miLogP: de partição octanol / água calculado; MM: massa molar; nON: aceptores de ligação de hidrogênio; e nOHNH: doador de ligação de hidrogênio.

Tabela 2. Propriedade dos compostos encontrados na espécie Arachis hipogaea, segundo o servidor SwissADME.

\begin{tabular}{lccc}
\hline Compostos & Druglikeness & Absorção Gl & Permeabilidade a BHE \\
\hline Araquidina -1 & Sim & Alto & Não \\
Araquidina -2 & Sim & Alto & Sim \\
Araquidina -3 & Sim & Alto & Sim \\
arahypin-1 & Sim & Alto & Sim \\
arahypin-2 & Sim & Alto & Não \\
arahypin-3 & Sim & Alto & Não \\
arahypin-4 & Sim & Alto & Não \\
\hline
\end{tabular}

Legenda: GI: gastrointestinal; BHE: barreira hematoencefálica.

Conforme verificado, todos os compostos selecionados da espécie Arachis hipogaea apresentaram potencial Druglikeness, de acordo com os parâmetros de Lipinsk ${ }^{14}$. A regra de Lipinsk, também denominada de regra dos 5, é amplamente utilizada para determinar as propriedades farmacocinéticas dos compostos e tem como objetivo avaliar a permeabilidade e solubilidade dos fármacos administrados por via oral.

De acordo com Lipinski14, é mais provável que uma molécula candidata seja ativa por via oral se o peso molecular (MM) for inferior a 500; coeficiente de partição octanol/água calculado ( $\log \mathrm{P}$ ) for inferior a 5 ; não mais do que 5 doadores de ligações de hidrogênio (grupos $\mathrm{OH}$ e 
$\mathrm{NH}$ ); e não mais de 10 aceptores de ligações de hidrogênio (notavelmente $\mathrm{N}$ e O).

Outro parâmetro avaliado nas moléculas candidatas a fármacos da espécie Arachis hipogea foi o perfil toxicológico, por meio do servidor ProtoxPredicition ${ }^{10}$. A plataforma ProTox- II $^{10}$ é dividida em cinco etapas de classificação, sendo elas a toxicidade aguda (toxicidade oral com seis classes de toxicidade), a toxicidade de órgãos, os parâmetros toxicológicos, as vias toxicológicas e as metas de toxicidade ${ }^{10}$. A classificação utilizada para este estudo foi a toxicidade aguda e os resultados encontrados por este servidor estão descritos na Tabela 3.

Tabela 3. Resultados encontrados para a toxicidade oral nos compostos selecionados da espécie Arachis hipogaea, segundo o servidor ProtoxPrediction.

\begin{tabular}{ccc}
\hline Compostos & Classe de toxicidade & LD50 \\
Araquidina -1 & 4 & $1190 \mathrm{mg} / \mathrm{kg}$ \\
Araquidina -2 & 4 & $1000 \mathrm{mg} / \mathrm{kg}$ \\
Araquidina -3 & 5 & $2560 \mathrm{mg} / \mathrm{kg}$ \\
arahypin-1 & 5 & $2560 \mathrm{mg} / \mathrm{kg}$ \\
arahypin-2 & 5 & $2320 \mathrm{mg} / \mathrm{kg}$ \\
arahypin-3 & 4 & $1500 \mathrm{mg} / \mathrm{kg}$ \\
arahypin-4 & 4 & $1500 \mathrm{mg} / \mathrm{kg}$ \\
\hline
\end{tabular}

Legenda: DL50: Dose Letal Mediana.

A triagem da toxicidade aguda é desenvolvida a partir de similaridade química entre compostos com efeitos tóxicos conhecidos e na presença de fragmentos tóxicos ${ }^{15}$. O grau de toxicidade é avaliado quantitativamente através do DL50 em $\mathrm{mg} / \mathrm{Kg}$ do peso corporal. $\mathrm{O} \mathrm{DL}_{50}$ é a dose letal mediana, ou seja, a dose necessária para que $50 \%$ dos indivíduos em testes morrem após o contado com o composto. Dessa forma, quanto menor o DL50, maior a toxicidade do composto ${ }^{15}$. As classes de toxicidade são categorizadas de acordo com o Sistema Globalmente Harmonizado de Classificação de Rotulagem de Produtos Químicos (GHS) (Tabela 4).
Tabela 4. Categoria de agentes tóxicos a partir da classificação GHS.

\begin{tabular}{ccc}
\hline Classificação & Categoria & DL50 \\
Classe I & fatal por ingestão & DL50 $\leq 5$ \\
Classe II & fatal por ingestão & $5<$ LD50 $\leq 50$ \\
Classe III & tóxico por ingestão & $50<$ LD50 $\leq 300$ \\
Classe IV & nocivo por ingestão & $300<$ LD50 $\leq 2000$ \\
& pode ser nocivo se & \\
ingerido & $300<$ LD50 $\leq 2000$ \\
Classe V & não tóxico & \\
& &
\end{tabular}

Legenda: DI50: Dose Letal Mediana.

Para obter o perfil de atividade biológica previsto para os compostos selecionados da Arachis hipogae foi utilizado o servidor PassPredicition ${ }^{11}$. Esse software avalia o potencial biológico de uma molécula semelhante a uma droga obedecendo aos critérios de Pa e Pi. Sendo que, Pa estima a chance de o composto ser ativo, e Pi estima a chance de o composto ser inativo ${ }^{11}$. Dos resultados encontrados por esta ferramenta, foram selecionados aqueles com potencial anticancerígenos, os quais estão descritos na Tabela 5.

Tabela 5. Provável atividade biológica antineoplásica encontrada para os compostos selecionados da Arachis hipogae.

\begin{tabular}{lccc}
\hline Composto & Atividade biológica & Pa & Pi \\
\hline & Agonista apoptótico & 0,845 & 0,005 \\
Araquidina-1 & TP53 potencializador & 0,752 & 0,017 \\
& Antineoplásico & 0,739 & 0,02 \\
& Antimutagênico & 0,717 & 0,005 \\
& MMP9 inibidor & 0,857 & 0,002 \\
& Agonista apoptótico & 0,851 & 0,005 \\
& Antimutagênico & 0,795 & 0,004 \\
& Antineoplásico & 0,75 & 0,018 \\
& & 0,745 & 0,018
\end{tabular}




\begin{tabular}{|c|c|c|c|}
\hline & JAK2 inibidor & 0,845 & 0,005 \\
\hline & Agonista apoptótico & 0,822 & 0,007 \\
\hline \multirow[t]{4}{*}{ Araquidina-3 } & TP53 potencializador & 0,751 & 0,017 \\
\hline & Antineoplásico & 0,735 & 0,02 \\
\hline & Antimutagênico & 0,713 & 0,006 \\
\hline & Agonista apoptótico & 0,818 & 0,007 \\
\hline \multirow[t]{2}{*}{ arahypin-1 } & TP53 potencializador & 0,729 & 0,02 \\
\hline & Antineoplásico & 0,727 & 0,022 \\
\hline
\end{tabular}

Legenda: Pa: Probabilidade de "estar ativo"; Pi: Probabilidade de "ser inativo".

A seleção dos resultados foi baseada em valores de $\mathrm{Pa}>$ 0,7 e valores de $\mathrm{Pi}<0,05$, ou seja, a probabilidade de ser ativo maior que $70 \%$ e a probabilidade de ser inativo menor que $5 \%$, respectivamente. Os resultados encontrados para os compostos mostram-se promissores para a ação anticancerígena.

Seguindo como base as prováveis atividades biológicas dos compostos, foi realizada a triagem de prováveis alvos biológicos através da verificação virtual da semelhança entre os ligantes conhecidos em um destino específico (alvo). A ferramenta utilizada para essa análise foi o servidor SwissTargetPredicion ${ }^{13} \mathrm{e}$ os dados obtidos estão descritos na Tabela 6.

Tabela 6. Resultado da predição de alvos biológicos a partir do servidor SwissTargetPredicion ${ }^{13}$ para os prováveis compostos antineoplásicos selecionados da espécie Arachis hipogea.

\begin{tabular}{cc} 
Composto & Atividade biológica \\
\hline Araquidina-1 & $\begin{array}{r}\text { subunidade p110-alfa da proteína quinase P13, Ciclo-oxigena- } \\
\text { se-1, Receptor alfa de estrogênio }\end{array}$ \\
Araquidina-2 & $\begin{array}{c}\text { Ciclo-oxigenase-2, Ciclo-oxigenase-1 e Receptor gama ativado } \\
\text { por proliferador de peroxissoma }\end{array}$ \\
Araquidina-3 & $\begin{array}{c}\text { Anidrase carbônica II, Anidrase carbônica XII e Anidrase carbô- } \\
\text { nica IX }\end{array}$ \\
& Transportador de norepinefrina, Anidrase carbônica VII e Ani- \\
drase carbônica III
\end{tabular}

Após utilizar as ferramentas e análises citadas anteriormente, verificou-se que a Araquidina-1 apresentou os resultados mais promissores e coerentes entre os compostos selecionados da espécie Arachis hipogea, e apontou como probabilidade mais relevante a atuação na subunidade alfa da proteína quinase P13 relacionada ao câncer de colo retal.

A Araquidina-1 (Ara-1) é um estilbeno derivado do género fenilpropanoide. Trata-se de compostos envolvidos no mecanismo de defesa contra agentes físicos e contaminação microbiológica ${ }^{17}$. Os estilbenos são sintetizados por uma variedade de espécie ${ }^{18}$. Na Arachis hipogae, por exemplo, esses compostos foram encontrados nas folhas, raízes e sementes da espécie ${ }^{19}$.

Os estudos de Higgs e colaboradore ${ }^{20}$ revelam que 0 amendoim possui valor nutritivo favorável. Além dos fitoquímicos, como fitoesteróis, fenólicos, estilbenos e arginina, a espécie é rica em fibras alimentares, proteínas e micronutrientes, que desencadeia efeitos cardioprotetor, anti-inflamatório e anticancer ${ }^{20}$. Na China, a pele do amendoim é utilizada para tratar hemorragia crônica e bronquite, enquanto na Nigéria os extratos da planta são utilizados para tratar pacientes diabéticos ${ }^{21}$.

Segundo os estudos realizados por Huang ${ }^{12}$, a Ara-1 apresenta sua eficácia como agente anticancerígeno ao induzir a morte celular programada nas células (PCD), por meio de ativação das Caspases. As Caspases são proteases sintetizadas por precursores inativos (pró-caspases) que se tornam ativas quando a célula recebe algum estímulo de morte externo (extrínseco), como por exemplo, radicais livres e agentes químicos e físicos ${ }^{22}$. Trata-se de uma via alternativa de morte de células cancerígenas com mutações nos principais genes apoptóticos ${ }^{12}$.

A Ara-1 também é descrita com potencial anti-inflamatório, apresentando maior potência inibitória à produção de prostaglandina e, portanto, podem ser de suma importância para o desenvolvimento farmacológico de nutracêuticos ou quimiopreventivos. Além disso, estudos também demonstram ação antioxidante da molécula, inibindo a formação de radicais livres e, consequentemente, a formação de tumor ${ }^{23}$. Após analisar as predições para atividade biológica da Araquidina-1 e seus alvos, apontou como probabilidade mais relevante a atuação na subunidade alfa da proteína quinase PI3.

As fosfatidilinositol 3-cinases (PI3K) consistem em uma família de cinases lipídicas de superfície celular, as quais tem por função regular as vias de sinalização envolvidas na proliferação e na sobrevivência celular, além da motilidade, adesão celular, diferenciação, rearranjo citoesquelético e tráfico intracelular ${ }^{24}$.

Os PI3Ks são subdivididos em 3 classes, sendo os PI3K de classe I (IA PI3K) aqueles que compreendem uma subunidade catalítica p110 e uma subunidade adaptadora reguladora ${ }^{25}$. A subunidade catalítica p 110 -alfa da fosfatidilin- 
ositol 3-quinase (PI3K), são codificadas pelo pro-oncogênese PIK3CA (subunidade catalítica fosfatidilinositol-4,5-bisfosfato 3-quinase alfa). A ativação da PI3K resulta em uma cascata de fosforização de proteínas envolvidas em diversos processos intracelulares, incluindo antiapoptose ${ }^{25}$.

Estudos revelam mutações na PIK3CA em vários tipos de câncer humano ${ }^{27}$. Em um estudo realizado por Samuels 28 mostraram que em 25 - 30\% de câncer de colorretal (CCR), aparece mutações somáticas na PIK3CA. Pesquisas realizadas também apontaram que as mutações PIK3CA contribuem para a tumorigênese, e são comumente observadas em cânceres colorretais humanos ${ }^{25}$.

No câncer de colorretal observa-se comumente a mutação no gene K-ras, que é uma proteína de membrana celular ${ }^{25}$. Sabendo que a K-ras oncogênico interage e ativa a PIK332, a ativação da via de sinalização da PIK3 por mutação no gene Kras ou PIK3CA foi considerada o mecanismo mais prevalente em pacientes com câncer colorretal ${ }^{29}$. Dessa forma, Khaleghpour ${ }^{29}$ conclui que, a p110-alfa, que é codificada pelo gene PIK3CA, é um alvo promissor para o desenvolvimento de drogas para o tratamento de câncer colorretal.

Diante de tais evidências na literatura, agregadas aos resultados do presente estudo in silico, o composto araquidina-1 foi selecionado para avaliação de potencial de interação com a subunidade catalítica p110-a de PI3K relacionado ao câncer de colorretal.

O câncer de colorretal (CCR) é uma neoplasia que acomete o colón e/ou reto. É a terceira neoplasia mais frequente no mundo e a segunda causa de morte nos Estados Unidos, tanto em homens quanto em mulheres. Os principais fatores de risco para essa patologia são o consumo excessivo de álcool, ingestão de gordura animal, tabagismo e falta de exercícios físicos ${ }^{33}$.

Essa neoplasia é considerada, portanto, uma doença de países ocidentais e industrializados devido ao consumo elevado de carnes, gordura e carboidratos nesses países, por isso a incidência em países como Estados Unidos, Canadá, Austrália e Nova Zelân$\mathrm{dia}^{34}$. O consumo elevado de gordura desencadeia o aumento da síntese de ácidos biliares que são mutagênicos e citotóxico ${ }^{33}$. Dessa forma, a ingesta de fibras insolúveis representa um fator de proteção contra o câncer, devido a redução da concentração de ácidos biliares e maior velocidade do trânsito intestinal ${ }^{35}$.

Diante a todo esse contexto, foi realizado uma pesquisa no Banco de Dados de Proteínas (do inglês, Protein Data Bank - PDB). Um banco de dados de proteínas e ácidos nucléicos tridimensionais cristalografados, através da difração de raios $X$. Buscou-se por meio desse banco de dados a estrutura proteica da subunidade alfa da proteína quinase PI3 humano (p110-a de PI3K) complexado a ligante. Abaixo, na Figura 1, segue sua estrutura tridimensional.

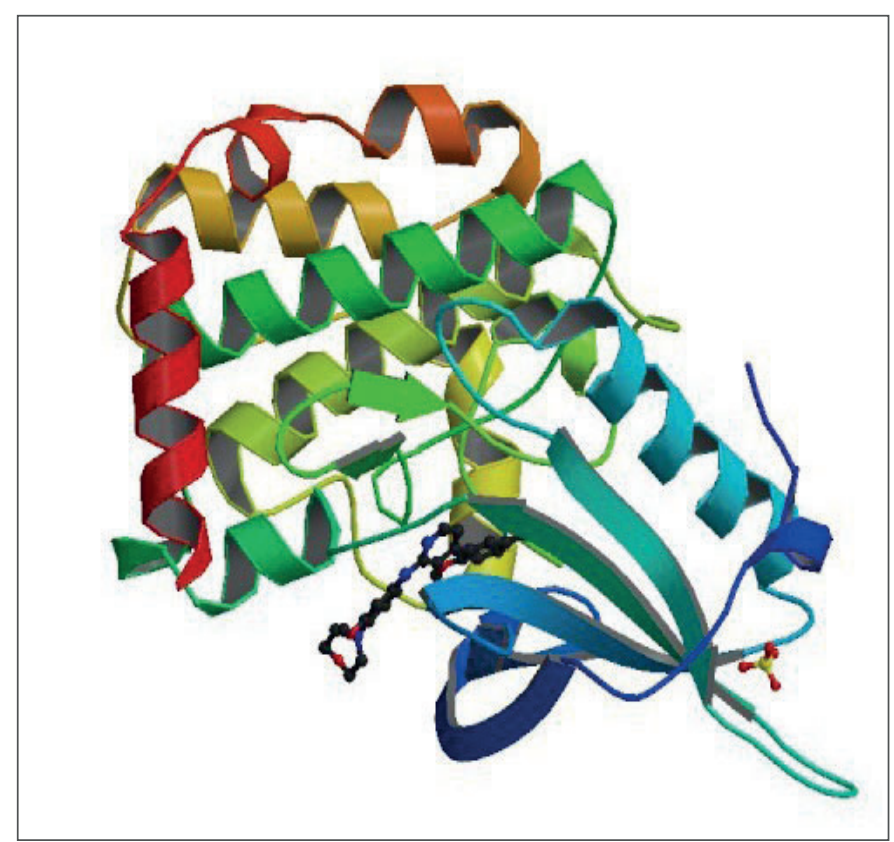

Figura 1. Representação tridimensional da proteína p110-alfa PI3K

Para realizar as simulações de docking molecular de ligantes contra a estrutura 3D da proteína alvo foi utilizado o programa MVD (Molegro Virtual Docker). O primeiro passo se deu através do redocking, ou seja, verificar se o protocolo de docking é suficientechemical c para recuperar as coordenadas atômicas da estrutura cristalográfica do domínio quinase do receptor TRAF2 ( $\mathrm{p} 110$-a de PI3K) com o inibidor 4-methoxy3-[2-[(3-methoxy-4-morpholin-4-yl-phenyl) amino]pyridin4-yl]benzenecarbonitrile. Tal simulação gera uma posição final para o inibidor, posição esta chamada pose, e compara com a posição cristalográfica, conforme mostra a Figura 2 abaixo:

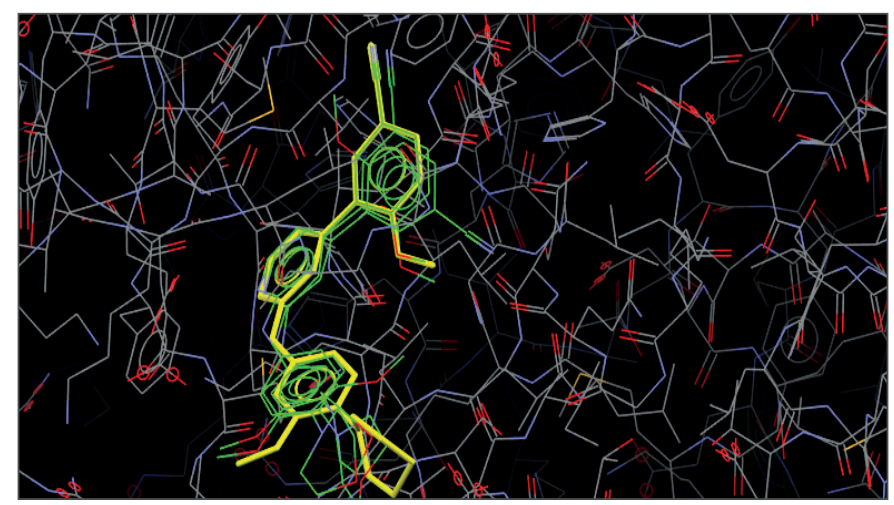

Figura 2. Análise de redocking para o alvo PDB ID 5AX9 (domínio quinase do receptor TRAF2) e seu respectivo ligante (4-methoxy3-[2-[(3-methoxy-4-morpholin-4-yl-phenyl)amino]pyridin-4-yl] benzenecarbonitrile) com as 3 melhores poses com valores de RMSD inferiores a 3. 
A distância entre a posição cristalográfica e a posição obtida computacionalmente é chamada RMSD (root-mean square deviation). Esta é aferida em Ansgtrons ( $(\AA)$ e valores menores que $2 \AA$ entre a pose e a posição cristalográfica, indicam sobreposição com grande proximidade. Os valores das 3 poses de referência RMSD para o redocking foram próximos de 1, ou seja, é possível verificar elevado grau de concordância entre o modelo empregado e a posição do ligante cristalografado.

A partir desta validação, o modelo empregado no redocking foi empregado para a molécula de araquidina-1 para avaliar seu potencial de interação com o alvo 5 AX9. Em cada pose são obtidas energias livres de ligação (entre ligante e alvo), onde a menor energia provavelmente justificará a conformação mais estável da interação ligante - alvo e prevê como ocorre a interação da molécula candidata com a cavidade ativa do alvo molecular. Sabe-se que as interações entre um fármaco e seu alvo proteico se dão por intermédio de forças intermoleculares do tipo dipolo-dipolo induzido, dipolo permanente e eventualmente ligações iônicas e covalentes. Dentre as forças dipolo-dipolo permanente estão as ligações de hidrogênio e nas dipolo-dipolo induzido são as forças de Van Der Walls ${ }^{36}$.

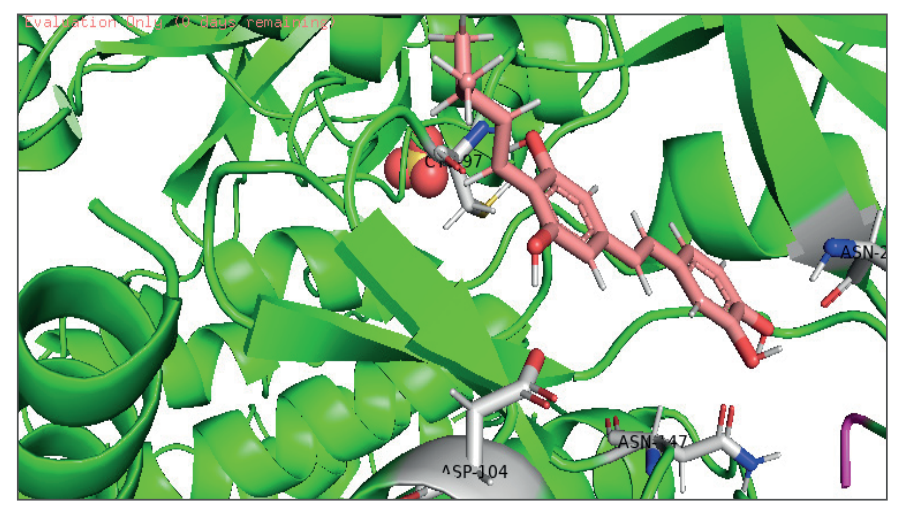

Figura 3. Imagem tridimensional do docking molecular da pose 1 (menos energética) da araquidina - 1 com o domínio quinase do receptorTRAF2 (A).

A Figura 4 demonstra o perfil em 2 dimensões da interação entre o ligante araquidina- 1 e o alvo molecular selecionado 5AX9. É possível identificar principalmente interações de natureza hidrofóbica entre os resíduos alquila dos aminoácidos assinalados e a porção hidrocarbônica do ligante. Além disso, a asparagina 22 e 147, aspartato 147 e cisteína 97 estabelecem ligações de hidrogênio com as hidroxilas da araquidina-1, o que corrobora a possibilidade deste ligante se manter ancorado no sítio ativo do alvo investigado.

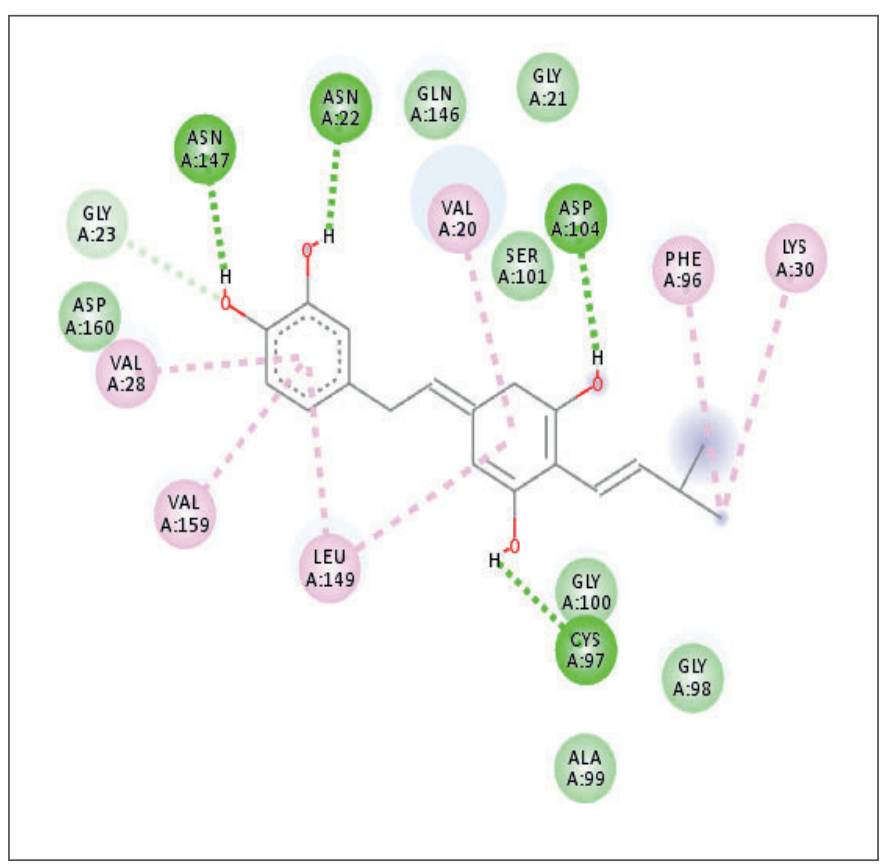

Figura 4. Diagrama de interação 2D entre a Araquidina-1 e a cavidade ativa da proteína PIKCA. Posição com maior escore na pontuação PLP fitness (Scoring Function CHEMPLP).

\section{Conclusão}

O composto natural Araquidina-1, extraído da espécie Arachis hipogae, apresenta um amplo espectro de bioatividade. As ferramentas de predição biológica revelaram resultados promissores para o tratamento do câncer de colorretal, por intermédio da molécula araquidina-1. Visto que se trata de um agente que possui estrutura química capaz de interagir e inibir o receptor $5 \mathrm{AX} 9$ (subunidade alfa p110 da proteína $\mathrm{PI} 3 \mathrm{~K}$ ), sendo um potencial candidato modificador da doença. A Araquidina-1, é portanto, um interessante ponto de partida para futuras investigações cujo objetivo é obter novas estratégias terapêuticas para o tratamento câncer de colorretal.

\section{Referências}

1. Firmo, W. C. A., Menezes, V. J. M., Passos, C. E. C., Dias, C. N., Alves, L. P. L., Dias, I. C. L., ... \& Olea, R. S. G. (2011). Historical context, popular use and scientific conception on medicinal plants. Cad Pesq, 18, 90-5.

2. Da Cunha, A. P. (2003). Aspectos históricos sobre plantas medicinais, seus constituintes activos e fitoterapia. da Cunha AP, da Silva AP, Roque OR. Plantas e produtos vegetais em fitoterapia. $4^{\mathrm{a}}$ ed. Lisboa: Fundação Calouste Gulbenkian.

3. Trindade, E. O. D. (2017). Do uso popular à concepção científica: plantas medicinais como tema contextual- 
izador no ensino de química orgânica.

4. Graciano, E. S. A. (2009) Estudos fisiológicos e bioquímicos de cultivares de amendoim (Arachis hypogaea L.) submetidas à deficiência hídrica. UFRP, Recife, fev.

5. Braga, G. C., Melo, P. S., Bergamaschi, K. B., Tiveron, A. P., Massarioli, A. P., \& Alencar, S. M.D. (2016). Extraction yield, antioxidant activity andphenolics from grape, mango and peanut agro-industrial by-products. Ciência Rural, 46, 1498-1504.

6. Lopes RM, Agostini-Costa T da S, Gimenes MA, Silveira D. Chemical Composition and Biological Activities of Arachis Species. J Agric Food Chem [Internet]. 11 de maio de 2011;59(9):4321-30.

7. Buzzi, F. D. C. (2007). Síntese de novas moléculas com potencial terapêutico: imidas cíclicas, chalconas e compostos relacionados.

8. Jarrahpour A, Fathi J, Mimouni M, Hadda T Ben, Sheikh J, Chohan Z, et al. Petra, Osiris and Molinspiration (POM) together as a successful support in drug design: antibacterial activity and biopharmaceutical characterization of some azo Schiff bases. Med Chem Res [Internet]. 9 de agosto de 2012;21(8):1984-90.

9. Daina A, Michielin O, Zoete V. SwissADME: a free web tool to evaluate pharmacokinetics, drug-likeness and medicinal chemistry friendliness of small molecules. Sci Rep [Internet]. 3 de maio de 2017;7(1):42717.

10. Banerjee P, Eckert AO, Schrey AK, Preissner R. ProTox-II: a webserver for the prediction of toxicity of chemicals. Nucleic Acids Res [Internet]. 2 de julho de 2018;46(W1):W257-63.

11. Lagunin A, Stepanchikova A, Filimonov D, Poroikov V.PASS: prediction of activity spectra for biologically active substances. Bioinformatics [Internet]. 1 de agosto de 2000;16(8):747 8.

12. Huang C-P, Au L-C, Chiou RY-Y, Chung P-C, Chen S-Y, Tang $\mathrm{W}-\mathrm{C}$, et al. Arachidin-1, a Peanut Stilbenoid, Induces Programmed Cell Death in Human Leukemia HL-60 Cells. J Agric Food Chem [Internet]. 8 de dezembro de 2010;58(23):12123-9.

13. Daina A, Michielin O, Zoete V. SwissTargetPrediction: updated data and new features for efficient prediction of protein targets of small molecules. Nucleic Acids Res [Internet]. 2 de julho de 2019;47(W1):W357-64.

14. Lipinski CA, Lombardo F, Dominy BW, Feeney PJ. Experimental and computational approaches to estimate solubility and permeability in drug discovery and development settings 1PII of original article:
S0169-409X(96)00423-1. The article was originally published in Advanced Drug Delivery Reviews 23 (1997). Adv Drug Deliv Rev [Internet]. março de 2001;46(1-3):3-26.

15. Drwal, M. N., Banerjee, P., Dunkel, M., Wettig, M. R., \& Preissner, R. (2014). ProTox: a web server for the in silico prediction of rodent oral toxicity. Nucleic acids research, 42(W1), W53-W58.

16. Ruppenthal, J.E. (2013). Toxicologia.Universidade Federal de Santa Maria, Colégio Técnico Industrial de Santa Maria. Rede e-Tec Brasil.

17. Pendse, R; Rao A.V; Venkataraman, K. 5,7-Dihydroxychromone from Arachis hypogaea shells. Phytochemistry, v. 12, p. 2033-2034, 1973.

18. Cassidy A, Hanley B, Lamuela-Raventos RM. Isoflavones, lignans and stilbenes - origins, metabolism and potential importance to human health. J Sci Food Agric [Internet]. 15 de maio de 2000;80(7):1044-62.

19. Tokuşoglu O, Unal MK, Yemiş F. Determination of the phytoalexin resveratrol (3,5,4'-trihydroxystilbene) in peanuts and pistachios by high-performance liquid chromatographic diode array (HPLC-DAD) and gas chromatography-mass spectrometry (GCMS). J Agric Food Chem [Internet]. 15 de junho de 2005;53(12):5003-9.

20. Higgs J. The beneficial role of peanuts in the diet - Part 2. Nutr Food Sci [Internet]. abril de 2003;33(2):56-64.

21. Lou H, Yamazaki Y, Sasaki T, Uchida M, Tanaka H, Oka S. A-type proanthocyanidins from peanut skins. Phytochemistry. 1999;51(2):297-308.

22. Spanos, S., Rice, S., Karagiannis, P., Taylor, D., Becker, DL, Winston, RML, \& Hardy, K. (2002). Atividade de caspase e expressão de genes de morte celular durante o desenvolvimento de embriões humanos pré-implantação. REPRODUCTION-CAMBRIDGE- , 124 (3), 353-363.

23. Chang J-C, Lai Y-H, Djoko B, Wu P-L, Liu C-D, Liu Y-W, et al. Biosynthesis Enhancement and Antioxidant and Anti-inflammatory Activities of Peanut ( Arachis hypogaea L.) Arachidin-1, Arachidin-3, and Isopentadienylresveratrol. J Agric Food Chem [Internet]. dezembro de 2006;54(26):10281-7.

24. Cantley LC. The Phosphoinositide 3-Kinase Pathway. Science (80- ) [Internet]. 31 de maio de 2002;296(5573):1655-7.

25. Ikenoue, Tsuneo, et al. "Análise funcional das mutações do gene PIK3CA no câncer colorretal humano." Cancer research 65.11 (2005): 4562-4567. 
26. Vivanco I, Sawyers CL. The phosphatidylinositol 3-Kinase-AKT pathway in human cancer. Nat Rev Cancer [Internet]. julho de 2002;2(7):489-501.

27. Gallia, G. L., Rand, V., Siu, I. M., Eberhart, C. G., James, C. D., Marie, S. K., ... \& Riggins, G. J. (2006). PIK3CA gene mutations in pediatric and adult glioblastoma multiforme. Molecular Cancer Research, 4(10), 709-714.

28. Samuels Y. High Frequency of Mutations of the PIK3CA Gene in Human Cancers. Science (80-) [Internet]. 23 de abril de 2004;304(5670):554-554.

29. Khaleghpour K, LiY, Banville D, Yu Z, Shen SH. Involvement of the $\mathrm{PI} 3$-kinase signaling pathway in progression of colon adenocarcinoma. Carcinogenesis. 2004 Feb;25(2):241-8. doi: 10.1093/carcin/bgg195. Epub 2003 Oct 24. PMID: 14578160.

30. Dong, Xin et al. Metamorphic rocks of the causes of southeastern Lhasa terrane and the Mesozoic - Cenozoic orogeny. Acta Petrologica Sinica, v. 28, n. 6, p. 1765-1784, 2012.

31. Xin, D., ZeMing, Z., Feng, L., Wei, W., Fei, Y., YanHao, L., ... \& ZhenYu, H. (2012). Genesis of the metamorphic rock from southeastern Lhasa terrane and the MesozoicCenozoic orogenesis. Acta Petrologica Sinica, 28(6), 1765-1784.

32. Rodriguez-Viciana, $\mathrm{P}$ et al. A fosfatidilinositol-3-OH quinase como alvo direto de Ras. Nature (Lond). v. 32, p. $370: 527,1994$.

33. Marley AR, Nan H. Epidemiology of colorectal cancer. Int J Mol Epidemiol Genet [Internet]. 2016;7(3):105-14.

34. Sung JJ, Lau JY, Goh K, Leung W. Increasing incidence of colorectal cancer in Asia: implications for screening. Lancet Oncol [Internet]. novembro de 2005;6(11):871-6.

35. Stigliano V. Early-onset colorectal cancer: A sporadic or inherited disease? World J Gastroenterol [Internet]. 2014;20(35):12420.

36. Florence, AT. Princípios Físico-Químicos em Farmácia Vol. 4. Edusp, 2003.

37. Martling A, Smedby KE, Birgisson H, Olsson H, Granath F, Ekbom A, et al. Risk of second primary cancer in patients treated with radiotherapy for rectal cancer. $\mathrm{Br} J$ Surg [Internet]. 3 de fevereiro de 2017;104(3):278-87. 